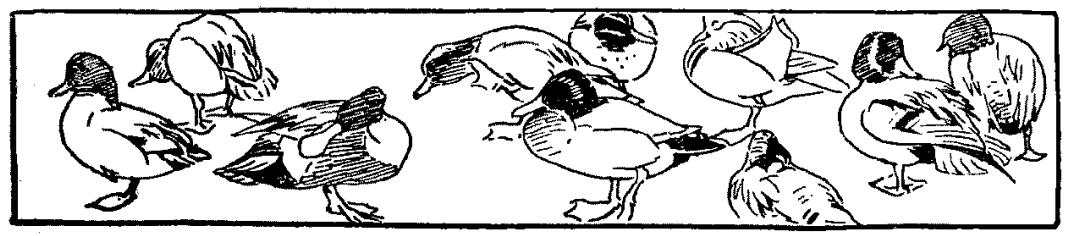

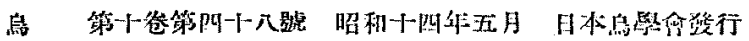

\title{
論說
}

\section{A NEW SUBSPECIES OF TROGLODYTES TROGLODYTES FROM THE BORODINO ISLANDS.}

By

Marquis Yamashina.

A collection of bird skins I have recently received from the Borodino Islands contained a specimen of a Wren. After having compared this material with 114 specimens ( 7 in Dr. Kuroda Coll., 27 in Mr. Momiyama Coll., 110 in Yamashina Coll.) of Troglodytes troglodytes distributed in the neighbouring countries I have found that this bird does not belong to any of the known subspecies. Therefore I describe it as a new subspecies which I propose to eall after Mr. H. Orii who twice explored the Borodino Islannls and collected many valuable specimens.

TROGLODYTES TROGLODYTES ORII, subsp. nov.

Diagnosis:-Crown, hind-neck, and mantle are much darker than those of $T$. t. fumigatus and T. t. attuno from Hondo and Kiusiu, and about the same as T. t. mosukei from Hachijô, the Seven Islands. Ground colour of rump, upper tail-coverts, tail- and wing-feathers is 
also similar to that of $T$. $t$. mosuled but black spots and black bars are darlier and wider than those of the latter subspecies except in the tail-feathers, where black bars are very narrow and numerous in the new subspecies. Chin, throat and upper-breast are rather pale, about the sime tone as those of T. $t$. fumigatus, and dark, transverse bars in these parts are almost invisible. Lower breast, flanks, and belly are also similar in colour to those of $T$. $t$. fumigatus, and far paler than those of $T$. $t$. utranoi and T. t. mosuket. This subspecies can easily be distinguished from $T$. t. ogruwe from Yakushima Island by its shorter bill and less rustic: colour of upper and lower parts, and from T. $t$. daurious, T. t. idius. T. t. peninsulae. and T. t. taivanus by its darker colour of upper and lower-parts.

Measurements:- Wimg $47 \mathrm{~mm}$.. tail $82 \mathrm{~mm}$., exposed culmen $11 \mathrm{~mm}$., tarsus $16.5 \mathrm{~mm}$.

Type:- Yamashina Ornithological Collection No. 25476. $\delta$ ad. Minami-daitôjima, one of the three Borodino Islands, east of the Riukiu Islands. Collected by Mr. Morimitsu Nagayama.

Note:- Troglodytes troglodytes is well distributed throughout the Eastern Asia including the Japanese Islands, and Formosa, but it has never been reported from the Riukiu Islands, and the occurence of a Wren from the Borodino Islands, some 200 miles from the nearest Riukiu Island, is very remarkable. 